International Journal of Child, Youth and Family Studies (2017) 8(1): 1-19

DOI: http://dx.doi.org/10.18357/ijcyfs81201716739

\title{
ADOLESCENTS NEGOTIATING ROMANTIC RELATIONSHIPS IN A CULTURALLY DIVERSE, URBAN COMMUNITY
}

\section{Catherine Ann Cameron, Toupey Luft, Dana Dmytro, Neringa Kubiliene, and Winni Chou}

\begin{abstract}
In this study we examined the negotiation of romantic relationships by urban youth, as discussed in focus groups, in a multicultural community. We compared these urban-student findings for an emergent fit with previously reported findings from more homogeneous groups of rural students. The unifying category, wrestling with gender expectations, which was identified in the rural studies, also emerged in the present study. A new unifying category represented urban participants' balancing cultural expectations in the contexts of their families and social groups. Three categories from the former rural studies emerged in the present urban study: making sacrifices, showing respect, and standing up for oneself; and a new category emerged: communicating. While the rural students identified media as critical contextual conditions for romantic relationships, the current urban teens identified digital and social media as crucial contextual conditions in dating relationships. Together, these findings suggest the importance of considering cultural and contextual aspects of youths' dating processes for developing a grounded theory that reflects aspects of teens' relational lives. Implications of this emergent theory are explored, and directions for future research are suggested.
\end{abstract}

Keywords: adolescents, romantic relationships, relational processes, gender, focused discussions, culture, digital social media

Catherine Ann Cameron (the corresponding author) is Honorary Professor in the Psychology Department, 2136 West Mall, University of British Columbia, Vancouver, BC V6T 1Z4.

Email: acameron@psych.ubc.ca

Toupey Luft is Associate Professor in the Master of Counselling Program at City University of Seattle in Canada, 120-1040 7th Ave SW, Calgary, AB T2P 3G9. E-mail: toupeyluft@cityu.edu

Dana Dmytro is a School Psychologist working in collaboration with the University of British Columbia, 2136 West Mall, Vancouver, BC V6T 1Z4. Email: DDmytro@sd35.bc.ca

Neringa Kubiliene is a PhD student in Interdisciplinary Graduate Studies at the University of British Columbia, 2080 West Mall, Vancouver, BC V6T 1Z2, Canada.

Email: neringa.ubc@gmail.com

Winni Chou is a Master of Occupational Therapy student at the University of British Columbia, 2329 West Mall, Vancouver, BC V6T 1Z4. Email: Winni_W_Chou@hotmail.com 
International Journal of Child, Youth and Family Studies (2017) 8(1): 1-19

Adolescents' processes, experiences and conceptualizations of navigating romantic relationships are developmentally significant because they inform and shape their current and future romantic relationships (Connolly \& McIsaac, 2011; Madsen \& Collins, 2011). Moreover, personal and interpersonal resilience and thriving depend on the degree to which romantic relationships are either enriching or disruptive (Dmytro, Luft, Jenkins, Hoard, \& Cameron, 2013; Friedlander, Connolly, Pepler, \& Craig 2013; Johnson, Giordano, Longmore, \& Manning, 2014). Much of the current literature on adolescent romantic relationships is focused on the problem of dating aggression and violence, where the perpetrators in heterosexual relationships are usually male. For instance, Bonomi, Anderson, Nemeth, Rivara, and Buettner (2013) studied the effects of a history of dating violence victimization on health in late adolescence. Recent research has focused on the link between use of digital and social technology and perpetrating abuse in these media (Lucero, Weisz, Smith-Darden, \& Lucero, 2014; Stonard, Bowen, Lawrence, \& Price, 2014). When gender is one of the variables under investigation, it often characterizes differences in the nature of perpetration and victimization (Hickman, Jaycox, \& Arnoff, 2004; Reyes, Foshee, Niolon, Reidy, \& Hall, 2015). Gender socialization research contains some acknowledgement that gender role adherence, in which males show more traditionally "masculine" behaviours and females show more traditionally "feminine" behaviours, is associated with dating violence (Peralta \& Tuttle, 2013).

There are few studies that focus on teens' engagement in and negotiation of healthy relationships, though Barber and Eccles (2003) provide a review of educational interventions in this area. In addition to the gap in understanding adolescents' processes in creating healthier romantic relationships, there is also a dearth of data regarding Canadian adolescents' dating initiation, prevalence, and duration. It is difficult to obtain current data on prevalence and on relevant characteristics of Canadian teenagers and their relationships. One primary source of information regarding North American teens' dating experiences, however, is the U.S. National Longitudinal Survey of Adolescent to Adult Health (ADD Health). Data obtained from ADD Health and reported by Carver, Joyner, and Udry (2003) showed that romantic relationships are common among American adolescents and the proportion of adolescents who report being in romantic relationships, as well as the duration of these relationships, increases with age.

In a U.S.-based study, Short, Catallozzi, Breitkopf, Auslander, and Rosenthal (2011) also reported that adolescent relationships are common, but indicated that several important elements are often ignored in current studies on teen intimacy, including the voices of the adolescents themselves, and the effect of gender on how intimate opposite-sex relationships evolve. In light of the above concerns the current study adds to the scholarly literature by including the voices of teenage boys and girls regarding their views on romantic relationships.

\section{Previous Research and Rationale for Current Study}

Connolly et al. (2014) concurred with Carver et al. (2003) that a majority of adolescents engage in romantic relationships. Connolly and her colleagues outlined Canadian youths' 
developmental sequence of romantic involvement in four stages: early adolescence (ages 12-14), middle adolescence (ages 15-17), late adolescence (ages 18-20), and emerging adulthood (ages 21-25). They reported that Canadian teens in early adolescence explore romantic feelings in the context of a group - not usually going on individual dates but socializing in mixed gender groups. Peers are the most common influence on those in the early adolescent years. According to Connolly et al., "Middle adolescents begin to form special romantic connections with other group members to whom they are attracted" (p. 11). Peers continue to be a strong influence when negotiating romantic relationships, while parents begin to exert more influence, especially in terms of monitoring romantic interchanges. In late adolescence and early adulthood, parents increasingly act as role models for relationships (Connolly et al., 2014). The authors called for romantic relationship research that is focused on two "emerging themes" (p. 15): the influence of technology, and examining youth experiences from a transcultural perspective (Connolly et al., 2014).

Two recent grounded theory studies (Dmytro et al., 2013; Luft et al., 2012) focused on rural teens and romantic relationships. In these studies, Canadian rural adolescent girls' and boys' processes of forming romantic heterosexual relationships were explained through a central organizing category: wrestling with gender expectations based upon what their peers expect of them. This overarching category was, in turn, represented in six communicative subcategories: determining responsibility/non-responsibility for interactions, keeping it in/letting it out in sharing feelings, standing up for oneself/backing down under pressure, making sacrifices/not making sacrifices for a relationship when dealing with family and friends, building trust/not trusting within a couple, and showing respect/showing disrespect for a partner. Participants identified media, including music videos, movies, and television shows, as a contextual condition (Corbin \& Strauss, 2008) that influenced how they struggled with gender expectations. Specifically, participants described how media's portrayals of gender, especially portrayals of females, influenced the ways in which they thought they should look or behave in the context of romantic relationships. A significant disadvantage of these two studies from the standpoint of generality was the lack of diversity in the ethnic and cultural backgrounds of these rural participants.

The current study therefore provides Canadian data from 2014 on teens' negotiation of romantic relationships in an urban, multicultural environment. We wanted to understand the views on developing and maintaining intimate relationships of adolescents from an ethnically and culturally heterogeneous environment. Additionally, since our rural studies in 2006, the use of digital and social media such as texting, Facebook, Instagram, and Twitter as methods of communication had increased significantly (Davis, 2013), and we were interested in whether they would play a greater role in the communications of these urban youth. Participants in this study discussed views on romantic relationships in researcher-facilitated, semi-structured focus groups held at school.

Following Wuest (2000), we took into consideration the earlier analyses of rural teens (Dmytro et al., 2013; Luft et al., 2012), and expanded upon the existing theory to incorporate how cultural influences might affect teens and their expressed views on romantic relationships. Using a 
International Journal of Child, Youth and Family Studies (2017) 8(1): 1-19

process of emergent fit (Charmaz, 2008; Wuest, 2000), we present a grounded theory incorporating the new data with the central strategy of "balancing cultural expectations". We used a constant comparative method (Corbin \& Strauss, 2008; Wuest, 2000) to develop a relevant theory grounded in the data (and the existing literature) that has wider applicability than a theory generated from only one source of data (cf. Wuest, 2000). The emergent fit approach to developing a theory was grounded in the words of the participants. Thus, we opted for a more emergent and constructivist model of data analysis, as advocated by Charmaz and Wuest, rather than the more prescriptive data analysis approach outlined by Corbin and Strauss. The specific differences in foci between these two models of grounded theory methodology appear in the study's data analysis and interpretation, and we highlight procedural intentions when appropriate.

\section{Method}

\section{Participants}

Following Patton's (2002) strategy for purposeful sampling, the researchers sought participation from those who were interested in discussing intimate relationships. Eligible participants were teenagers who were students in one public high school in a western, multicultural Canadian city of approximately 600,000 inhabitants. Fifty adolescents (27 female) ranging in age from 16 to 18 years $(M=16.38)$ took part in this study.

Participants were enrolled in Grades 11 (72\%) and 12 (28\%). In this sample, 22\% were foreign-born, mostly from Asia. Forty-six percent of the total sample self-identified as Asian, 18\% as South Asian, and $16 \%$ as Caucasian. The remaining $20 \%$ of the sample included five students of mixed ancestry, two Pacific Islanders, one Hispanic student of Latin American ancestry, one student of African ancestry, and one of Thai ancestry. Home family-language reports indicated that $30 \%$ of the students in our sample spoke English at home, while the other $70 \%$ spoke one of more than 20 language groups at home.

Ninety-four percent of the students identified themselves as heterosexual, while $6 \%$ identified as bisexual. With regard to dating history, 58\% reported not having dated and 10\% reported going on romantic dates less than 10 times a month; 16\% had a steady partner for less than six months; and $14 \%$ had a steady partner for more than six months. Two percent did not respond to this question.

\section{Data Collection and Analysis}

Permission to meet with the participating students and to hold focused group discussions with them on the general topic of adolescent romantic relationships was obtained from the local school board and the school principal, who introduced the researchers to a teacher agreeable to facilitating small-group discussions during classroom periods. The collaborating teacher scheduled five focused discussion sessions for researchers to meet with participants. 
International Journal of Child, Youth and Family Studies (2017) 8(1): 1-19

Two groups were mixed gender, one group was male, and two groups were female. One mixed-gendered discussion was held during a psychology class, and the other mixed-gendered discussion was held with students during a home economics class. The single-gender discussions were held simultaneously during a psychology class. Prior to participating in the study, students submitted consent letters signed by their parents in addition to personally signing participant assent forms.

On the day of the discussions, the research assistants who served as group facilitators introduced themselves to the participants. The facilitators stated that the purpose of the study was to gain further knowledge regarding how teens make sense of romantic relationships. The research team also assured participants that there were no adverse consequences for not participating and that they were free to withdraw at any time.

The youths were asked to discuss dating relationships, regardless of the extent of their personal dating experience or sexual orientation. In the event that students did not have personal dating experience, they were encouraged to share the dating experiences of their peers without identifying those involved in the stories. Next, ground rules were established that highlighted respectful listening and respectful speaking. It was emphasized that everything said in the room should stay in the room and, to broaden and facilitate discussion and to maintain confidentiality, participants were asked to speak in the third person and to talk about others without using names. To prompt the discussion, a very brief ice-breaking skit was conducted. Facilitators asked for two volunteers from the class, (one boy and one girl, prior to splitting into single and mixed gendergroups), who enacted a situation where one dating partner became jealous because the other partner seemed to be suspiciously sending text messages to someone else on their phone.

All discussions were audiotaped and then transcribed verbatim by members of the research team independently who then checked for consensus on the accuracy of the transcriptions with another member who had been present during the focus discussions. Names of participants mentioned during the group discussions were not recorded in the transcripts to protect participants' anonymity.

Data analysis proceeded concurrently as transcripts were produced. Data were analyzed using the constant comparative procedure utilized when developing a grounded theory (Corbin \& Strauss, 2014; Wuest, 2000). Congruent with emergent fit methodology, relevant scholarly literature was reviewed to compare for emerging fit with the developing theory (cf. Charmaz, 2008; Wuest, 2000). The systematic review of the transcripts resulted in the development of codes and categories. These codes and categories were compared to those that came from the previous studies with rural youth in a more ethno-culturally homogeneous sample. We were informed by the methods of Charmaz (2008), Glaser (1978), and Wuest (2000) in attending to the new data to ensure that we were not enforcing a pre-existing theory on the data - instead, we carefully ensured that the emerging theory was grounded in the current data. If categories of the previous theory (Dmytro et al., 2013; Luft et al., 2012), did not fit conceptually with the emergent categories observed here, 
International Journal of Child, Youth and Family Studies (2017) 8(1): 1-19

they were not included. Further, we expanded on some of the previous theory's categories based on our new information.

\section{Findings}

Although we invited discussion of lesbian, gay, bisexual, transgender, or queer (LGBTQ) romantic relationships, no students explicitly mentioned or discussed such relationships. This omission is addressed in the discussion section regarding future research. Analysis of the current study's discussions revealed that engaging in and carrying on romantic relationships is a complicated, multi-faceted process for urban teens in a multicultural community. There are a number of contextual factors that influence the participants, including socio-cultural and religious expectations, gender role adherence, and the use of social media. The influence of these factors will be outlined further in the discussion of the emerging theory's categories below.

We utilize the term "cultural factors" with the understanding that culture does not just refer to people varying on the basis of race or ethnicity. Following Arthur and Collins (2010), we start from a balanced approach on culture and cultural inquiry in that we acknowledge that there are many ways that people can vary, and we do not make assumptions about what these many variations mean to them (religion, gender, sexual orientation, country of origin, etc.). We recognize that there are some common factors among members of a cultural group, but that there are also commonalities across cultural groups, and that both might inform our understanding (Collins, 2010).

A majority of the processes outlined in Dmytro et al. (2013) and Luft et al. (2012) remain central contextual factors relevant to the present group's views on romantic relationships. In particular, gender roles and related expectations stand out in the present data as they did in our earlier work. However, current participants' responses to gender roles and related expectations were mediated by one or more cultural factors that will be outlined further below.

\section{Balancing Cultural Expectations}

For participants, figuring out how to balance cultural expectations with regard to potential romantic relationships was identified as a central process influenced by their interactions with peers and with family members. Balancing cultural expectations involves considering factors pertaining to the self, and then deciding how to proceed, even though there may be peer or parental pressure to choose conventionally. In general then, the participants spoke of considering the cultural expectations of peers and parents when negotiating romantic relationships, but in the end stated that they would probably follow their own will in their romantic interactions. A small number of participants explained that if there were familial disapproval of their partners, they would hide their romantic relationships from their parents, even though it would result in relational tensions within the family. This applied to situations where parents might disapprove of a potential romanticinterest candidate from an ethnicity or religious background different from the participant. As one participant said, "You kind of just don’t tell them." Several students agreed with this strategy, 
International Journal of Child, Youth and Family Studies (2017) 8(1): 1-19

explaining that they would rather make individual choices for getting involved in romantic relationships, and then hide their actions from their parents to retain both their autonomy and familial harmony. As one boy stated, “If your parents don't approve [of] someone that you are in a relationship with, you might have to keep them more secretive”. On a more broadly cultural level, one of the girls offered:

Yeah, and also in my culture, it's okay if you marry your cousin, so, it's a bit weird. So when I see some in my culture not following the rules, then I'm like, “Then why am I still doing this?”

Another small number of participants stated that they would communicate openly with their parents, and a small number would even seek relationship advice from a parent.

Our current multi-ethnic sample of participants expressed more hesitation regarding initiating and engaging in romantic relationships than the more culturally homogeneous and rural youths in the Dmytro et al. (2013) and Luft et al. (2012) studies. These urban adolescents weighed the costs and benefits of dating within the social systems of their peers and members of their family.

\section{Wrestling with Gender Expectations in Cultural Context}

As in our earlier work (Dmytro et al., 2013 and Luft et al., 2012), the teens in this study's urban, multi-ethnic sample spoke of gender roles being a consistent consideration in dating. Gender expectations were intertwined with cultural norms. Eaton and Rose (2011), through their analysis of dating literature over the past 35 years, found that gender scripting has been a highly influential factor when people of any age are engaged in intimate relationships. Further, Gevers, Jewkes, Mathews, and Flisher (2012) highlight the primacy of gender role expectations reported by teens in South Africa as they negotiate heterosexual dating interactions. The transcript data from this study of urban teens in a multicultural community show confirmations of the present relevance of gender roles, as well as clear expressions of moving away from them.

First, the participants in the current study mentioned discomfort about what the other gender expects in a heterosexual relationship. One female student complained, "[girls] always need to look good ... [boys] expect that from a girl.” Some boys expressed concern over media portrayals perpetuating “manly men” stereotypes. These boys felt that those who did not adhere to masculine stereotypes of being the more powerful or directive one in a heterosexual relationship were prone to ostracism by others: "Manly men are kind of in charge more.... [Some people] alienate anyone different from the stereotypes.” Some girls spoke of boys' struggles in conforming to gendered expectations, as evidenced by treating girls certain ways, for example, by making grand gestures or buying gifts for them.

Second, although some youths commenced the focused discussions by mentioning gender stereotypes such as women cooking and men paying for a first date, as the discussions progressed, these stereotypes began to be contested. For example, a girl asserted that, "both should pay, like 
International Journal of Child, Youth and Family Studies (2017) 8(1): 1-19

you pay this one, I will pay the next one.” There were thus indications of urban youth gravitating toward a more egalitarian view, despite initially expressing ingrained gender stereotypes. This is consistent with Eaton and Rose's (2011) findings of some slight deviation from strict gender roles, such as more women initiating dates.

\section{Communicating}

Communicating with romantic partners was a relational process that initially emerged from rural adolescents' discussions, and appeared again in the urban teens' groups. In the rural discussion groups, girls described the benefits of open, reciprocal communication, or letting it out (Luft et al., 2012), whereas boys emphasized processes of keeping it in, which signified not sharing as many details with an intimate partner (Dmytro et al., 2013). For the urban teens in this study, this process of communicating was less about choosing from just two options (such as keeping things to oneself or not). Overall, the urban participants seemed to value communication skills, particularly being “assertive” as opposed to "passive aggressive”. One girl indicated that she would communicate assertively if she were worried about something going on in the relationship:

Don't ask them if they're hiding anything just discuss [it] with them, "Are you okay?" "Is there something going in the relationship or is there something else that you're not comfortable telling me yet?” But just don’t be all sneaky.

Communicating effectively was portrayed as a process whereby both parties in a relationship enter into negotiations in their communications. Participants often mentioned communicating effectively when discussing the importance of trust in building romantic relationships. Participants agreed that mistrust in an intimate relationship leads to passive or aggressive communication strategies and isolation. These consequences of poor communication were similar to what the rural sample outlined in the process of not trusting. In the rural teens' discussions, building trust/not trusting referred to the process of building confidence and assurance in a dating relationship partner. Similarly, urban students considered building trust through communication to be a fundamental part of a healthy relationship. One boy stated, "A relationship can only grow to a certain point if there's no trust involved.... Trust is kinda the foundation of a relationship or a friendship."

Social media are deployed to mediate communication strategies for these urban teenagers. For many, social media represent a less direct way to communicate in a relationship. According to participants, casually texting instead of having "real” (face-to-face) communication could create conflicts over such matters as changing one’s relationship status on Facebook. Several participants lamented teenagers' lack of confidence in engaging in direct communication; they found verbal conversations, either over the phone or face-to-face, challenging.

\section{Making Sacrifices}

Within the rural teens' discussions, this process involved giving up something for the wellbeing of a romantic relationship. Urban youths made sacrifices to enhance their romantic 
International Journal of Child, Youth and Family Studies (2017) 8(1): 1-19

relationships but they also described how one might make sacrifices in the context of their family. Sacrifices made to enhance one's relationship were undertaken to promote relational positivity. As one boy said:

If this person had club activity every day from (I don’t know), 8 to 8, 24 hours, or whatever ... And suddenly the person he's in a relationship with wants to do something at the exact same time. He must be able to give up that activity for that time to spend time with the person he's in a relationship with, because that shows he's willing to sacrifice things and therefore promote a healthy relationship by commitment.

Urban teens said that overall, romantic relationships require sacrifices from each member and a failure to make certain sacrifices can sour the relationship. The following quote from one participant illustrates how refusing to make sacrifices could result in acrimony:

My friend, every single Sunday she comes to church and her significant other [says], “Oh, let’s hang out on Sunday or something” and [she says], "No I gotta go to church.” And [he says], "No just skip church and blah, blah, blah ...”

Thus, the couple started an argument rather than resolving the issue by coming to a mutual understanding of each other's priorities. As indicated previously, sometimes teens sacrificed being open with their families about being in a relationship. However, not everyone felt the need to conform to parental cultural and religious values. One participant stated that ultimately, individuals should decide on their own partner because: "If you truly do want to be with that person, then maybe you have to let your family get used to it because in the end you are not going to be spending every day with your parents”.

\section{Standing Up for Oneself and Showing Respect or Disrespect}

In the rural youths' studies, these two categories involved how participants negotiated responses to situations that they saw as controlling or abusive, while for the urban participants, these categories were closely intertwined and were collapsed into one unit during data analysis. The urban teens spoke of relational abuse and how both intimate "cheating” and verbal and physical abuse were clear ways of a partner showing disrespect. One girl spoke of a partner who was "always like questioning, 'Oh, what are you doing? Why are you doing this?” as a sign that the relationship was unhealthy and as an indication of a need to stand up for oneself. Generally, for the urban participants, fewer actions were recounted with regard to "standing up for themselves". The discussions focused more on hypothetical examples than on actual actions taken in relationships. This may be due to the fact that many participants had not yet engaged in a long-term intimate relationship.

Though both male and female participants seemed equally aware of respect issues that might arise in relationships, it was primarily girls who spoke in detail of the factors surrounding 
International Journal of Child, Youth and Family Studies (2017) 8(1): 1-19

respect. For instance, urban girls saw "sub-tweeting” — intimate partners posting derogatory messages online - as disrespectful, passive aggressive, and unacceptable. Urban girls also discussed other issues related to respect, agreeing, as one participant expressed, that it is "probably important to set boundaries with each other" as a way of standing up for oneself in the relationship.

\section{Religion and Culture, and Standing Up for Oneself}

Religious and cultural affiliation were also discussed by participants as factors for how young people engage in showing respect or disrespect; or as factors constraining how one might "stand up for oneself” in an intimate relationship. For example, some saw arranged marriages as showing disrespect by the family for the dating process:

... because he never had a chance to get to know the person or choose a person to actually be with to have kids with and have a whole family.... It's a big boundary and it's a really big argument and conflict.

One girl stated that boys have more freedom to stand up for themselves by dating anyone they want. "Guys have the authority to change into a different religion. Girls can't." This perceived relative lack of freedom to stand up for oneself due to being female was highlighted by another girl in the quote given earlier, also expressing her desire to overcome it: "So when I see some people in my culture not following the rules then I think, 'Then why am I still doing this?'” Another spoke of how she deals with the pressure within her culture to have a partner: "Well I don't really care, I just ignore them.” Some youth mentioned how being in Canada has made their parents more openminded. One participant offered:

Well, since like the old times I think my parents ... Oh they’re more open-minded now, because of culture and like ... They're in Canada right now too, so like it influences you, where you are, how people treat each other and stuff I guess.

Another participant challenged the idea of gender inequality in religions by stating, "religion-wise, at least from my religion, it's always equal, means they become more open-minded.” Finally, one boy spoke of the importance of being accepting of all cultures, avoiding extremism and cultural exclusivity. Overall, the participants' views showed some commonalities with regard to certain aspects of culture - specifically, ethnic groupings, religion, and gender. However, they also acknowledged some common factors between members of these groups, pointing out the importance of respect and communication.

\section{Digital and Social Media as a Contextual Condition}

This study takes place in an era when digital and social media are emerging as prevalent methods of communication that are far more personal and sharable than print media, television and movies (Davis, 2013). This context lies in contrast to the setting of the rural youth participants, who were interviewed just a few years earlier, when digital and social media were less developed and pervasive than today. The urban youths' discussions revolved a great deal around digital and 
International Journal of Child, Youth and Family Studies (2017) 8(1): 1-19

social media, which currently play significant roles in these adolescents' romantic relationship processes. Participants in this study spoke of texting as a way to begin a relationship, and as a significant indication of dating progression. As one girl put it, "I feel the interest starts in the real world, and then if you guys start texting, it's kind of like, 'Now we're texting."” These participants felt that the onset of texting signalled the true beginning of the relationship.

Posting frequent relationship updates on Facebook or other social media can create problems. As another girl said, “[in such cases,] there's no privacy in your relationship - you're just sharing it to the world". Not sharing relationship updates on social media can also be problematic, as in one girl's example showing that this can lead to the false impression that one is available to date:

They got criticism just because they didn’t change their [social media status], and they're like, “Oh are you trying to expose yourself as 'Oh, I’m still free?’”

Problems can also arise when individuals “like” or comment on someone other than their partner's posts or pictures. The participants indicated that confusion and conflict sometimes occur when they look at their partner's texts or Facebook messages, or read a tweet and wonder if the message is directed at them. It is regarded as not uncommon for adolescents to post relationship issues indirectly (such as sub-tweeting) and to engage in passive-aggressive communication online. Overall, the urban adolescents in the study used digital and social media to establish and maintain communication with partners and others, and sometimes, wittingly or unwittingly, to sabotage their relationships.

\section{Discussion}

The urban teens in the current study, residing in a multicultural, metropolitan city, described the central process of balancing cultural expectations; both this process and that of wrestling with gender expectations permeated all subcategories that emerged: communication, making sacrifices, and standing up for oneself and showing respect/disrespect. In the studies with rural groups, discussions of romantic relationships focused more on the two dating partners and highlighted media influences as contextual conditions on these partner interactions, whereas the urban teens identified how digital/social media as the contextual condition is instrumental in influencing intimate relationship processes and focused more on how to approach intimate relationships, reflecting their less direct interpersonal experience compared to the rural youth. Considering the demographics of the urban sample, this finding would be consistent with previous findings that Asian Canadian youth are less actively involved in romantic relationships compared to European Canadians (Li, Connolly, Jiang, Pepler, \& Craig, 2010).

Results of the current study revealed both similarities and differences in relationship processes compared to the rural teens. Urban participants in a multicultural setting discussed the role of cultural norms and expectations in their decision-making process related to their relationship navigation. Similar to the rural teens, the urban youth described wrestling with gender expectations; 
however, this process was influenced by cultural norms specific to participants' gender. The urban girls in particular identified gender-specific issues in their process of wrestling with gender expectations, influenced by both parents and cultural dictates regarding intercultural relationships. In spite of their awareness of stereotypical gender norms, these participants' attitudes seemed to be somewhat egalitarian, consistent with Eaton and Rose’s (2011) findings.

Communication was discussed in a more nuanced way by the urban teens than the rural teens. Whereas rural girls described the benefits of open communication and boys advocated more restraint, urban teens of both genders highlighted the importance of communication in building trust. Communication for the urban teen participants is also an essential strategy used to balance cultural expectations, in that they are required to negotiate their own desires and their parents' expectations, in addition to negotiating and communicating these issues with their partners. Although these participants seemed keenly aware of the importance of communication skills in building healthy relationships, previous studies have found a discrepancy between teens' knowledge and their actual communication skills (Cameron et al., 2007; Dmytro et al., 2013).

The central role of family for urban teens was also indicated in their discussions of making sacrifices. Both urban and rural teens discussed making sacrifices for the sake of their partners; however, the urban teen sample also talked about the necessity of making sacrifices for the sake of one's family. For example, urban teens at times feel the need to hide relationships from their parents, or disengage from dating someone altogether based on their parents' expectations, which may be strongly influenced by cultural values.

The rural teens gave many more examples of their experiences regarding the need to stand up for oneself in the context of a romantic relationship, whereas the urban teens mostly discussed hypothetical situations. Showing respect or disrespect and standing up for oneself were interrelated for the urban teens, and they discussed setting boundaries when partners show disrespect. For the urban teens, the unique issue discussed was their need to stand up to their parents when balancing their own and their parents' dating expectations, which are primarily influenced by cultural values. Urban teens, due to the rise of social media, were also keenly aware of the potential for disrespect to be shown through online forums, such as Facebook and Instagram. These concerns are echoed in Stonard et al.'s (2014) discussion of the role of electronic communication technology in facilitating teen dating violence and abuse.

Because the rural and urban data were taken several years apart, secular trends could explain some of the urban-rural differences in digital and social media adoption. While rural teenagers did not mention digital and social media just a few years earlier, these media sources emerged as a significant part of the context of urban teens' dating discussions.

\section{Implications: Digital and Social Media}

Today's urban adolescents face numerous relational challenges that reflect not only interpersonal concerns, but also cultural and media influences. However, these challenges might 
International Journal of Child, Youth and Family Studies (2017) 8(1): 1-19

effectively be addressed with the help of youth-friendly and media-aware families, educators, and community leaders. The results of this study suggest it is important to focus specifically on issues arising from digital and social media in adolescents' intimate relationships, since our results show that increasingly, youths are using these media platforms to initiate, display, and manage their relationships.

Educational measures involving communications awareness, media (and social media in particular), media literacy, and skill development can support adolescents' healthier use of media. An online website, Media Smarts: Canada’s Centre for Digital and Media Literacy (n.d.) provides curricula, action guides, and training programs that educators can access for use in their classrooms (see Steeves, 2014). Austin, Pinkleton, Hust, and Cohen (2005) and Pinkleton, Austin, Chen, and Cohen (2013) found that adolescent education on media literacy led to their more critical consumption of media related to tobacco use and of media related to sexual behaviour.

Educational curricula can focus on increasing adolescents' awareness that media can create trends and norms, and that not all of them are desirable. Strategies can be presented and discussed by trusted adults and peer facilitators to assist adolescents in resisting those issues that they find incompatible with their personal and cultural core values. An exploration of core values in the context of critical adolescent identity development can include topics of great interest to many adolescents. Educators can assist adolescents in identifying and developing ways to instantiate foundational values, such as trust, in their romantic relationships, in order to enhance their desire to engage in healthier relationships, rather than model their dating behaviour on gender and cultural norms conveyed through the media.

On another level, youth advocates can become catalysts for facilitating such conversations not only at school with their peers, but also at home and in the larger community. To help adolescents see the importance of determining boundaries between private and public spheres and learn how to protect themselves online, community partners can engage with them through casual conversations, planned workshops within existing curricula, and community-sponsored youthoriented public discussions. Finally, teenagers can be encouraged to reflect on the risks and rewards of digital and social media in open discussions that can provide relevant lessons through real-life cases of online exposure, self-disclosure, and fraud.

\section{Implications: Youth in a Multicultural Setting}

Urban youths in this study spoke about engaging in a process that involved balancing individual preferences with parental expectations. In contrast, the rural youth from the earlier work did not identify or describe such a process as being a part of their dating relationships. Educators and counsellors should be aware of the influence of culture and religion on the youths with whom they work, and also consider that teens may be unaware of the ways in which they are influenced by cultural norms. As Arthur and Collins (2010) advocate, educators and counsellors should develop specific awareness and competencies regarding various aspects of culture such as race, religion, and gender. They need to remain mindful that their own cultural identity will likely 
influence how they see other people and what they value when working with others professionally. As much as counsellors and educators are called to learn about various cultural factors, they must also take care to ask a client or student how they define themselves and to begin to think of identities as "intersectional" (Hulko, 2009). For example, those who work with youth from an intersectional perspective can take into consideration how social class intersects with ethnic background, and consider how the former may not be as significant as the latter from the youth's perspective. Treating students or clients with respect and not making assumptions about how cultural factors may influence them can allow educators and counsellors to move towards social justice in their work (Arthur \& Collins, 2010).

Our sample included many Asian and South Asian students who generally start dating at a later age than students of Caribbean or European origin (Connolly, Craig, Goldberg, \& Pepler, 2004). Dhariwal and Connolly (2013) found that this later onset of dating behaviour held for adolescents in China and in India as well. Connolly et al. (2014) attributed Asian adolescents' later engagement in romantic relationships to the more collectivistic nature of Eastern culture, whereby familial input is of great importance to dating initiation and choices. Bicultural students may feel caught between two worlds if they try to adhere to more traditional cultural or religious values at home while their peers expect them to evince different values at school (Cone, Buxton, Lee, \& Mahotiere, 2014; Sharabany, Eshel, \& Hakim, 2008). This experience of being caught between family and school cultures and contexts can be intensified if the students have emigrated from a traditional community, or if they are born to immigrant parents (Bauer, Loomis, \& Akkari, 2013).

\section{Limitations}

Two of the five discussion groups were mixed-gender, which may have attenuated the expression of gender differences compared to the rural youths in the earlier study, who engaged exclusively in single-gender focus groups. Overall, there was a tendency in both rural and urban discussions for girls to be more talkative than boys. Boys in an all-male group with a male facilitator tend to be more expressive than boys in mixed-gender discussion groups (Cameron, 2004). Thus, single-gender focus groups are recommended in research on gendered topics such as intimate relational processes, as has been suggested by several of the present authors (Cameron, 2004; Luft et al., 2012; Dmytro et al., 2013).

In 2017, rural youths also participate actively in social media. Future research may reveal even greater prevalence of social media in negotiating adolescent relationships, wherever those relationships develop (O’Sullivan, 2012). Further, the influence of the ethnic and cultural diversity in the current urban sample potentially overpowers differences from the rural sample that might otherwise be attributed to community size and setting.

Finally, it is necessary to challenge and augment the heteronormative nature of these findings by more explicitly inviting the voices and perspectives of LGBTQ youth on intimate relationships. As gender-variant people and those with non-dominant sexual orientations are often the targets of bullying at school (Wright \& Perry, 2006), it would be important to engage in more 
International Journal of Child, Youth and Family Studies (2017) 8(1): 1-19

anonymous ways of gathering such data so that young people who identify as queer or questioning would feel safer about participating.

\section{Future Directions}

Collins, Welsh, and Furman (2009) and Connolly et al. (2014) emphasized the need to speak with ethnically diverse participants. Our study explores a multicultural sampling of youth in one Canadian city. Future research could extend this inquiry to other urban centres. Ultimately, cross-national samples could be investigated. From our urban youth discussions, there is a clear need for a deepened exploration of differing ethnic groups' parent-teen struggles, as well as more research on youths' negotiating intimate partner relationships. Many of our urban, multicultural youths were first-generation Canadians, placing these teens in a particularly challenging position wherein they attempt to adapt to both their parents' traditional culture, and to the majority culture as it is portrayed in media; as it is experienced with their school peer groups; and as it is required elsewhere in their lives. Inter-ethnic dating relationships are on the increase (Uskul, Lalond, \& Konanur, (2011), and cultural differences can compound relational differences in communication styles. Also, differing views on sexuality increase the potential for conflict.

The youths in this study expressed concerns regarding the influences of gendered expectations, culture, and media, and they spoke about resistant actions they might take to counter oppressive aspects of those influences. Future research in this area could examine how best to assist youth resisting the more pernicious influences of gender stereotypes, media distortions of dating, and cultural expectations regarding romantic relationships, in order to continue to create healthier dating relationships. This work could involve identifying and supporting how youth use social media to resist some of the cultural and gender limitations, or the oppression they experience. Ultimately, research of this kind will ground interventions for healthier teen dating relationships in the words and actions of teens themselves.

\section{Acknowledgements}

This research would not have been possible without the participation of the teenage students, the collaborating teacher, the high school principal, and the school district involved. We heartily thank them all for their contributions and cooperation. 
International Journal of Child, Youth and Family Studies (2017) 8(1): 1-19

\section{References}

Arthur, N., \& Collins, S. (Eds.). (2010). Culture-Infused Counselling. Calgary, AB: Counselling Concepts.

Austin, E. W., Pinkleton, B. E., Hust, S. T., \& Cohen, M. (2005). Evaluation of an American Legacy Foundation/Washington State Department of Health media literacy pilot study. Health Communication, 18(1), 75-95. doi:10.1207/s15327027hc1801_4

Barber, B. L., \& Eccles, J. S. (2003). The joy of romance: Healthy adolescent relationships as an educational agenda. In P. Florsheim (Ed.), Adolescent romantic relations and sexual behavior: Theory, research, and practical implications (pp. 355-370). Mahwah, NJ: Lawrence Erlbaum Associates.

Bauer, S., Loomis, C., \& Akkari, A. (2013). Intercultural immigrant youth identities in contexts of family, friends, and school. Journal of Youth Studies, 16(1), 54-69. doi:10.1080/ 13676261.2012.693593

Bonomi, A. E, Anderson, M. L., Nemeth, J., Rivara, F. P., \& Buettner, C. (2013). History of dating violence and the association with late adolescent health. BioMed Central Public Health, 13, 820. doi:10.1186/1471-2458-13-821

Cameron, C. A. (2004). Schools are not enough: It takes a whole community. In M. L. Stirling, C. A. Cameron, N. Nason-Clark, \& B. Mediema (Eds.), Understanding abuse: Partnering for change (pp. 269-294). Toronto, ON: University of Toronto Press.

Cameron, C. A., Byers, E. S., Miller, A., McKay, S. L., St. Pierre, M., Glenn, S., \& the Provincial Strategy Team for Dating Violence Prevention. (2007). Dating violence prevention in New Brunswick. Fredericton, NB: Muriel McQueen Fergusson Centre for Family Violence Research.

Carver, K., Joyner, K., \& Udry, J. R. (2003). National estimates of adolescent romantic relationships. In P. Florsheim (Ed.), Adolescent romantic relations and sexual behavior: Theory, research, and practical implications (pp. 23-56). Mahwah, NJ: Lawrence Erlbaum Associates.

Charmaz, K. (2008). Constructionism and grounded theory. In J. A Holstein \& J. F. Gubrium (Eds.), Handbook of constructivist research (pp.397-412). New York, NY: Guilford.

Collins, S. (2010). Women on the margins: Honouring multiple and intersecting cultural identities. In L. Ross (Ed.), Counselling women: Feminist issues, theory, and practice (pp. 21-50). Toronto, ON: Canadian Scholars’ Press / Women’s Press.

Collins, W. A., Welsh, D. P., \& Furman, W. (2009). Adolescent romantic relationships. Annual Review of Psychology, 60, 631-652. doi:10.1146/annurev.psych.60.110707.163459 
International Journal of Child, Youth and Family Studies (2017) 8(1): 1-19

Cone, N., Buxton, C., Lee, O., \& Mahotiere, M. (2014). Negotiating a sense of identity in a foreign land: Navigating public school structures and practices that often conflict with Haitian culture and values. Urban Education, 49(3), 263-296. doi:10.1177/ 0042085913478619

Connolly, J., Craig, W., Goldberg, A., \& Pepler, D. (2004). Mixed-gender groups, dating, and romantic relationships in early adolescence. Journal of Research on Adolescence, 14 (2), 185-207. doi:10.1111/j.1532-7795.2004.01402003.x

Connolly, J., \& McIsaac, C. (2011). Romantic relationships in adolescence. In M. K. Underwood \& L. H. Rosen (Eds.), Social development: Relationships in infancy, childhood, and adolescence (pp. 180-197). New York, NY: Guilford.

Connolly, J., McIsaac, C., Shulman, S., Wincentak, K., Joly, L., Heifetz, M., \& Bravo, V. (2014). Development of romantic relationships in adolescence and emerging adulthood: Implications for community mental health. Canadian Journal of Community Mental Health, 33(1), 7-19. doi:10.7870/cjcmh-2014-002

Corbin, J., \& Strauss, A. (2008). Basics of qualitative research: Techniques and procedures for developing grounded theory (3rd ed.). Thousand Oaks, CA: Sage. Accessed via http://dx.doi.org.ezproxy.library.ubc.ca/10.4135/9781452230153

Davis, K. (2013). Young people’s digital lives: The impact of interpersonal relationships and digital media use on adolescents' sense of identity. Computers in Human Behavior, 29, 2281-2293. doi:10.1016/j.chb.2013.05.022

Dhariwal, A., \& Connolly, J. (2013). Romantic experiences of homeland and diaspora South Asian youth: Westernizing processes of media and friends. Journal of Research on Adolescence, 23(1), 45-56. doi:10.1111/j.1532-7795.2012.00803.x

Dmytro, D., Luft, T., Jenkins, M., Hoard, R., \& Cameron, C. A. (2013). Rural adolescent boys’ negotiating heterosexual romantic relationships: "We need to sacrifice our brains." Canadian Journal of Counselling and Psychotherapy, 47(3), 361-382. Accessed via http://cjc-rcc.ucalgary.ca/cjc/index.php/rcc/article/download/2666/2496

Eaton, A. A., \& Rose, S. (2011). Has dating become more egalitarian? A 35-year review using Sex Roles. Sex Roles, 64(11), 1-20. doi:10.1007/s11199-011-9957-9

Friedlander, L. J., Connolly, J. A., Pepler, D. J., \& Craig, W. M. (2013). Extensiveness and persistence of aggressive media exposure as longitudinal risk factors for teen dating violence. Psychology of Violence, 3(4), 310-322. doi:10.1037/a0032983 
International Journal of Child, Youth and Family Studies (2017) 8(1): 1-19

Gevers, A., Jewkes, R., Mathews, C., \& Flisher, A. (2012). 'I think it's about experiencing, like, life’: A qualitative exploration of contemporary adolescent intimate relationships in South Africa. Culture, Health \& Sexuality, 14(10), 1125-1137. doi:10.1080/13691058.2012. 723752

Glaser, B. G. (1978). Theoretical sensitivity: Advances in the methodology of grounded theory. Mill Valley, CA: Sociology Press.

Hickman, L. J., Jaycox, L. H., \& Aronoff, J. (2004). Dating violence among adolescents: Prevalence, gender distribution, and prevention program effectiveness. Trauma, Violence, \& Abuse, 5(2), 123-142. doi:10.1177/1524838003262332

Hulko, W. (2009). The time- and context-contingent nature of intersectionality and interlocking oppressions. Affilia, 24(1), 44-55. doi:10.1177/0886109908326814

Johnson, W. L., Giordano, P. C., Longmore, M. A., \& Manning, W. D. (2014). Intimate partner violence and depressive symptoms during adolescence and young adulthood. Journal of Health and Social Behavior, 55(1), 39-55. doi:10.1177/0022146513520430

Li, Z. H., Connolly, J., Jiang, D., Pepler, D., \& Craig, W. (2010). Adolescent romantic relationships in China and Canada: A cross-national comparison. International Journal of Behavioral Development, 34(2), 113-120. doi:10.1177/0165025409360292

Lucero, J. L., Weisz, A. N., Smith-Darden, J., \& Lucero, S. M. (2014). Exploring gender differences: Socially interactive technology use/abuse among dating teens. Affilia: Journal of Women and Social Work, 29(4), 478-491. doi:10.1177/0886109914522627

Luft, T., Jenkins, M., \& Cameron, C. A. (2012). Rural adolescent girls negotiating healthy and unhealthy romantic relationships. Canadian Journal of Counselling and Psychotherapy, 46(3), 259-276. Accessed via: http://cjc-rcc.ucalgary.ca/cjc/index.php/rcc/article/ viewFile/1570/2426

Madsen, S. D., \& Collins, W. A. (2011). The salience of adolescent romantic experiences for romantic relationship qualities in young adulthood. Journal of Research on Adolescence, 21(4), 789-801. doi:10.1111/j.1532-7795.2011.00737.x

Media Smarts, Canada’s Centre for Digital and Media Literacy. (n.d.) Re: Digital \& media literacy. Retrieved from http://mediasmarts.ca/digital-media-literacy/digital-issues

O’Sullivan, L. F. (2012). Open to the public: How adolescents blur the boundaries online between the private and public spheres of their lives. [Editorial]. Journal of Adolescent Health, 50(5), 429-430. doi:10.1016/j.jadohealth.2012.03.001

Patton, M. Q. (2002). Qualitative research and evaluation methods (3rd ed.). Thousand Oaks, CA: Sage. 
International Journal of Child, Youth and Family Studies (2017) 8(1): 1-19

Peralta, R. A., \& Tuttle, L. A. (2013). Male perpetrators of heterosexual-partner-violence: The role of threats to masculinity. Journal of Men's Studies, 21(3), 255-276.

doi:10.3149/jms.2103.255

Pinkleton, B. E., Austin, E. W., Chen, Y., \& Cohen, M. (2013). Assessing effects of a media literacy-based intervention on US adolescents' responses to and interpretations of sexual media messages. Journal of Children and Media, 7(4), 463-479. doi:10.1080/ 17482798.2013.781512

Reyes, H. L., Foshee, V. A., Niolon, P. H., Reidy, D. E., \& Hall, J. E. (2015). Gender role attitudes and male adolescent dating violence perpetration: Normative beliefs as moderators. Journal of Youth and Adolescence, 44(2), 350-360. doi:10.1007/s10964-015-0278-0

Sharabany, R., Eshel, Y., \& Hakim, C. (2008). Boyfriend, girlfriend in a traditional society: Parenting styles and development of intimate friendships among Arabs in school. International Journal of Behavioral Development, 32(1), 66-75. doi:10.1177/ 0165025407084053

Short, M. B., Catallozzi, M., Breitkopf, C. R., Auslander, B. A., \& Rosenthal, S. L. (2011). Adolescent intimate heterosexual relationships: Measurement issues. Journal of Pediatric and Adolescent Gynecology. 26(1), 3-6. doi:10.1016/j.jpag.2011.09.010

Steeves, V. (2014). Young Canadians in a wired world, Phase III: Sexuality and romantic relationships in the digital age. Ottawa, ON: MediaSmarts. Retrieved from http://mediasmarts.ca/ycww

Stonard, K. E., Bowen, E., Lawrence, T., \& Price, S. (2014). The relevance of technology to the nature, prevalence, and impact of adolescent dating violence and abuse: A research synthesis. Aggression and Violent Behaviour, 19, 390-417. doi:10.1016/j.avb.2014.06.005

Uskul, A. K., Lalond, R. N, \& Konanur, S. (2011). The role of culture in intergenerational value discrepancies regarding intergroup dating. Journal of Cross-Cultural Psychology, 42(7), 1165-1178. doi:10.1177/0022022110383311

Wright, E. R., \& Perry, B. L. (2006). Sexual identity distress, social support, and the health of gay, lesbian, and bisexual youth. Journal of Homosexuality, 51(1), 81-109. doi:10.1300/J082v51n01_05

Wuest, J. (2000). Negotiating with helping systems: An example of grounded theory evolving through emergent fit. Qualitative Health Research, 10(1), 51-70. doi:10.1177/ 104973200129118246 